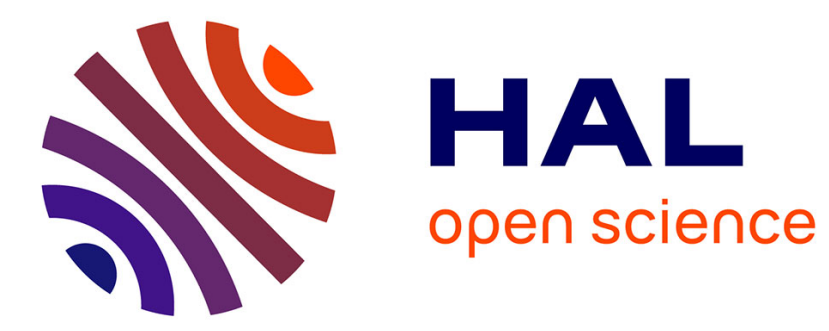

\title{
Strength Use in the Workplace: A Literature Review
}

Marine Miglianico, Philippe Dubreuil, Paule Miquelon, Arnold Bakker, Charles Martin-Krumm

\section{To cite this version:}

Marine Miglianico, Philippe Dubreuil, Paule Miquelon, Arnold Bakker, Charles Martin-Krumm. Strength Use in the Workplace: A Literature Review. Journal of Happiness Studies, 2020, 21 (2), pp.737-764. 10.1007/s10902-019-00095-w . hal-02932138

\section{HAL Id: hal-02932138 \\ https://hal.univ-lorraine.fr/hal-02932138}

Submitted on 7 Sep 2020

HAL is a multi-disciplinary open access archive for the deposit and dissemination of scientific research documents, whether they are published or not. The documents may come from teaching and research institutions in France or abroad, or from public or private research centers.
L'archive ouverte pluridisciplinaire HAL, est destinée au dépôt et à la diffusion de documents scientifiques de niveau recherche, publiés ou non, émanant des établissements d'enseignement et de recherche français ou étrangers, des laboratoires publics ou privés. 


\title{
Strength Use in the Workplace: A Literature Review
}

\author{
Marine Miglianico $^{1,5}$ - Philippe Dubreuil ${ }^{1}$ Paule Miquelon ${ }^{1} \cdot$ Arnold B. Bakker $^{3,4}$. \\ Charles Martin-Krumm ${ }^{2,5,6,7}$
}

(c) Springer Nature B.V. 2019

\begin{abstract}
The objective of the present article is to review the literature on strengths use and development in the workplace. This review (1) presents a summary of the outcomes of strengths use in organizations, and (2) proposes a general intervention model facilitating strengths development in the workplace. A systematic review was used to summarize the outcomes of studies on strengths use at work, whereas a narrative review was employed to examine the main strengths development interventions available, and to propose an integrative model. Results indicate that strengths use is associated with job satisfaction, work engagement, well-being, and work performance. Furthermore, scholars and professionals use similar intervention strategies that can be summarized in a five-step integrative model to promote strengths development in organizations. We discuss the theoretical and practical implications, as well as avenues for future research.
\end{abstract}

Keywords Strengths · Organizations · Intervention · Positive psychology

\section{Introduction}

When an organization is faced with problems associated with burnout, personnel turnover, and absenteeism, the question of personal and professional fulfillment is paramount. The positive psychology movement has expanded mental health knowledge beyond a focus on alleviating illness and mental disorders. This approach is defined as "the study of the conditions and processes that contribute to the flourishing or optimal functioning of people, groups and institutions" (Gable and Haidt 2005, p. 104). It is considered the most rigorous

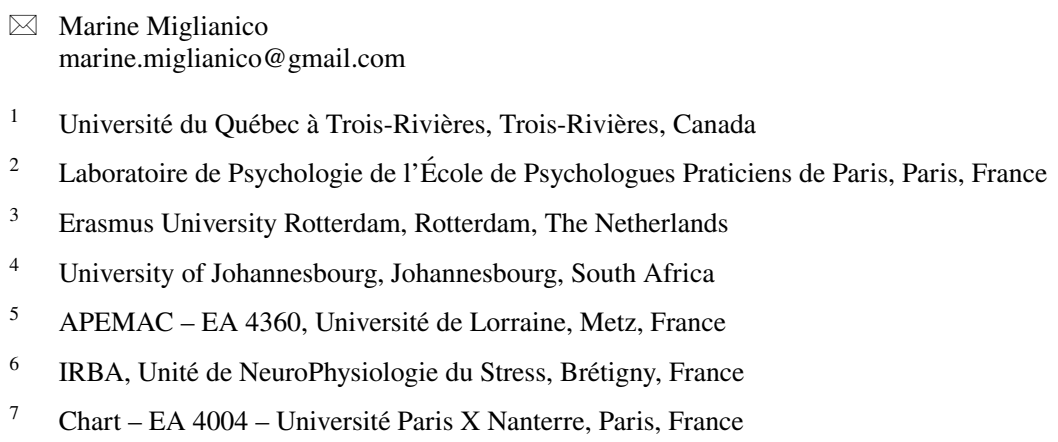


scientific approach for studying positive human experiences, and its popularity has generated much interest in the scientific community (Mongrain and Anselmo-Matthews 2012; Seligman 2012; Seligman et al. 2005).

Positive psychology is intended to complement the traditional deficit approach. Indeed, human beings appear to have a natural inclination to devote greater attention to the negative or dysfunctional (Sheldon and King 2001). This negativity bias has been addressed in numerous studies, the results of which have led to the rapid implementation of new and reliable evaluation strategies as well as effective treatments (Nathan and Gorman 1998; Seligman 1994).

Organizations still seem to cultivate this deficit culture (Bouskila-Yam and Kluger 2011; Roberts et al. 2005a). Most organizations seem to take employee strengths for granted and emphasize minimizing weaknesses instead (Buckingham and Clifton 2001). Managers tend to identify and then manage deficits by seeking to correct employees' dysfunctional skills, abilities, attitudes or behaviors (Luthans 2002) through training, feedback, and coaching (Linley et al. 2009; Van Woerkom et al. 2015). While such an approach can potentially help employees to improve skills and performance, this approach can be demoralizing and therefore less effective than focusing on individual strengths (Hodges and Clifton 2004). Moreover, studying deficits and dysfunctions cannot reveal the unique impact of strengths (Buckingham and Clifton 2001). In fact, the best opportunity for individual development lies in investing in people's strengths, not in managing their weaknesses (Linley et al. 2009; Roberts et al. 2005b). In other words, minimizing weaknesses can prevent failure but cannot inspire excellence.

In recent years, strengths have been the subject of much research (Hodges and Clifton 2004; Linley 2008; Roberts et al. 2005b), and many experts have called for the development of valid interventions that can be applied in the field (Proctor et al. 2011; Proyer et al. 2015; Quinlan et al. 2012). Considering the ever increasing volume of research conducted in this area and the demand for empirically validated guidelines for conducting strengths development interventions, it seems important to review the current knowledge on strengths use and development in organizational environments in order to shed light on existing data in a more structured and critical way.

Previous work has been conducted in this regard by Quinlan et al. (2012) and more recently by Ghielen et al. (2017). Quinlan et al. (2012) first reviewed eight strengths interventions studies using experimental or quasi-experimental designs. Results indicated significant increases in different measures of well-being in all intervention studies. Ghielen et al. (2017) extended the latter work by conducting a review of strengths interventions studies published between 2012 and 2017. Eighteen (quasi-) experimental studies were identified through a systematic literature search. Results showed that strengths interventions performed in a wide variety of contexts had positive effects on a broad range of outcomes, including well-being (e.g., positive affect, life satisfaction, depression), job outcomes (e.g., work performance, work engagement), personal growth initiative and group outcomes (e.g., information sharing, class cohesion).

Our review extends previous work by Quinlan et al. (2012) and Ghielen et al. (2017) in three significant ways. First, we concentrated our review solely on studies conducted in the workplace, as it is an area in which strengths application is particularly active and highly relevant. Second, whereas both previous reviews focus on intervention studies, we also included correlational studies in order to provide a thorough and comprehensive portrait of the scientific knowledge available. Third, we investigated various strengths development strategies used in the workplace in order to provide additional insights on the optimal design of strengths interventions and propose an integrative model for applied settings. 
The objective of the present article is therefore to review the literature on strengths use and development in the workplace. This literature review is intended to (1) provide a summary of the outcomes of strengths use in organizations, and (2) propose an integrative model based on the main intervention steps found in the literature regarding strengths development in the workplace. To this end, the three principal strengths approaches and their associated measurement instruments will first be described, followed by the methodology employed in order to meet our dual objective. Then, results related to the use of strengths in the workplace will be presented and discussed. Likewise, the intervention steps necessary to successfully foster the development of employee strengths in organizations will be described and discussed. As a final analysis, a general discussion will follow, in which we will review our main findings and comment our study.

\section{Studying and Developing Strengths}

Strengths is an important topic of study for several reasons. First, strengths fluctuate and can develop continuously over the course of a lifetime (Biswas-Diener 2006; Park et al. 2006). For example, in the United States, hope, teamwork or enthusiasm seem to be more common among youth than adults, while appreciation of beauty, authenticity, leadership or openness seem to be more common among adults (Park et al. 2006). Cultural institutions that encourage strengths and virtues have also been identified in many different cultures (Biswas-Diener 2006). This suggests that strengths development is advantageous within evolution, and could thus be expected to be part of successful societal functioning.

Second, to the individual who holds them, strengths appear so natural as to seem self-evident (Buckingham and Clifton 2001). Interfering with values and actions, strengths are often simply seen as "the right thing to do" by the person, a habit more than a singular behavior. Some researchers suggest that these behavioral patterns may be anchored in neural networks, which would explain the ease with which they are used by the person, and the sense of authenticity and energy resulting from their use (Buckingham and Clifton 2001; Linley 2008). For this reason, strengths can also be ignored or discredited (Biswas-Diener et al. 2011; Buckingham and Clifton 2001). The individual may then miss out on a great opportunity for personal development.

Third, better understanding strengths seems to be highly beneficial not only for individuals, but also for organizations, since exercising them has a positive impact on employee wellbeing and performance (Dubreuil et al. 2016; Harzer and Ruch 2016; Littman-Ovadia et al. 2017). Employees who are actively encouraged to use their strengths at work handle their workload more effectively and show lower levels of absenteeism (Van Woerkom et al. 2016a), while experiencing higher levels of vitality, flow, passion and engagement at work (Dubreuil et al. 2014; Forest et al. 2012; Lavy and Littman-Ovadia 2017; Van Woerkom et al. 2015). As a result, organizations that rely on employees' strengths see productivity, sales, and profit increase (Hodges and Asplund 2010), while at the same time increasing employee satisfaction, pleasure, commitment, and meaning (Harzer and Ruch 2012, 2013). 


\section{Strengths in the Scientific Literature}

An extensive look at the scientific literature shows that the strengths movement has been developed over time by three main schools of thought, which mutually influenced each other and therefore propose comparable, but slightly different definitions, classifications, and measurement instruments to characterize strengths. As the concept of strengths is based on different streams of research, integrating these three visions makes it possible to develop a better understanding of the field and approach the concept in a broader and more comprehensive perspective.

The Gallup Institute developed a first school of thought. Clifton and his colleagues (Buckingham and Clifton 2001) have studied excellence in a wide variety of sectors for several decades. They identified 34 talents that constitute the foundation of exceptional performance. Each combination of talents is unique to the individual, and reflects his/ her field of excellence and path of development. According to these authors, a strength is defined as "a constant near perfect performance in an activity" (Buckingham and Clifton, p. 25), and has three components: talent, knowledge, and skills (Clifton and Harter 2003). Talent is defined as a "naturally recurring pattern of thought, feeling or behavior". The key to strength development lies in the identification of talents, and refinement of these by developing knowledge (facts and experiences) and skills (steps of an activity) (Asplund et al. 2014).

Clifton and his team identified hundreds of talent themes, which they refined into 34 major ones (Buckingham and Clifton 2001; Clifton et al. 2002). The StrengthsFinder was built for individuals to identify their own key talents via an electronic questionnaire (Buckingham and Clifton 2001). A revised version, the StrengthsFinder 2.0, was developed later (Rath 2007). It is comprised of 177 pairs of items representing potential self-descriptors (e.g., "I get to know people individually"; "I accept many types of people"). The respondent must choose on a five-point scale the statement that best describes him or her, and indicate the extent to which it describes him or her (i.e., 1-"Strongly describes me [Option A]", 3-Neutral, 5-"Strongly describes me [Option B]"). The participant is given $20 \mathrm{~s}$ to respond before the system moves on to the next pair of items. Reliability studies conducted on multiple samples $(n=2219 ; 46,902 ; 250,000)$ indicate that Cronbach's alpha estimates vary between .52 and .78 for the 34 strengths themes and test-retest correlations range between .53 and .80 for a 6-months period. Factor analyses reported suggest a four-factor structure comprised of the main themes of executing, influencing, relationship building, and strategic thinking, although complete results of these analyses are not provided (Asplund et al. 2014).

Inspired by the early work of Clifton and his colleagues, Peterson and Seligman (2004) developed a second school of thought. Their seminal handbook Character Strengths and Virtues: A Handbook and Classification (Peterson and Seligman 2004) describes and classifies the strengths and virtues that enable human beings to flourish (Seligman et al. 2005). To establish this classification, the authors studied philosophical, religious, and psychological writings from around the world (Dahlsgaard et al. 2005) to draw out elements that are valued universally, regardless of culture or historic period.

Peterson and Seligman (2004) define character strengths as the core psychological ingredients that define moral virtues (see Table 1). They are neither secondary nor epiphenomenal to what is negative in human beings, but rather are singular entities. They are both relatively stable and malleable in the individual (Biswas-Diener et al. 2011; Peterson and Seligman 2004). Their occurrence depends on context, individual values, personal 
Table 1 Strengths classifications

\begin{tabular}{llll}
\hline StrengthsFinder talents & & & \\
\hline Achiever & Connectedness & Harmony & Relator \\
Activator & Consistency & Ideation & Responsibility \\
Adaptability & Context & Includer & Restorative \\
Analytical & Deliberative & Individualization & Self-assurance \\
Arranger & Developer & Input & Significance \\
Belief & Discipline & Intellection & Strategic \\
Command & Empathy & Learner & Woo \\
Communication & Focus & Maximizer & \\
Competition & Futuristic & Positivity & \\
\hline
\end{tabular}

VIA strengths

\begin{tabular}{|c|c|}
\hline Virtues & Associated strengths \\
\hline \multirow[t]{5}{*}{ Wisdom } & 1. Creativity \\
\hline & 2. Curiosity \\
\hline & 3. Judgment \\
\hline & 4. Love of Learning \\
\hline & 5. Perspective \\
\hline \multirow[t]{4}{*}{ Courage } & 1. Bravery \\
\hline & 2. Honesty \\
\hline & 3. Perseverance \\
\hline & 4. Zest \\
\hline \multirow[t]{3}{*}{ Humanity } & 1. Kindness \\
\hline & 2. Love \\
\hline & 3. Social Intelligence \\
\hline \multirow[t]{3}{*}{ Justice } & 1. Fairness \\
\hline & 2. Leadership \\
\hline & 3. Teamwork \\
\hline \multirow[t]{4}{*}{ Temperance } & 1. Forgiveness \\
\hline & 2. Humility \\
\hline & 3. Prudence \\
\hline & 4. Self-regulation \\
\hline \multirow[t]{5}{*}{ Transcendence } & $\begin{array}{l}\text { 1. Appreciation of } \\
\text { beauty and excel- } \\
\text { lence }\end{array}$ \\
\hline & 2. Gratitude \\
\hline & 3. Hope \\
\hline & 4. Humor \\
\hline & 5. Spirituality \\
\hline
\end{tabular}

Strengths profile strengths

\begin{tabular}{llll}
\hline Action & Curiosity & Incubator & Prevention \\
Adaptable & Detail & Innovation & Pride \\
Adherence & Drive & Judgment & Rapport builder \\
Adventure & Emotional awareness & Legacy & Relationship deepener \\
Authenticity & Empathic & Listener & Resilience \\
\hline
\end{tabular}


Table 1 (continued)

\begin{tabular}{llll}
\hline Strengths profile strengths & & \\
\hline Bounceback & Enabler & Mission & Resolver \\
Catalyst & Equality & Moral compass & Self-awareness \\
Centered & Esteem builder & Narrator & Self-belief \\
Change agent & Explainer & Optimism & Service \\
Compassion & Feedback & Organizer & Spotlight \\
Competitive & Gratitude & Persistence & Strategic awareness \\
Connector & Growth & Personal responsibility & Time optimizer \\
Counterpoint & Humility & Personalisation & Unconditionality \\
Courage & Humor & Persuasion & Work Ethic \\
Creativity & Improver & Planner & Writer \\
\hline
\end{tabular}

interests, and the presence of other strengths. Ten criteria define character strengths (Peterson and Seligman 2004): (1) They contribute to the development of oneself and others; (2) They are morally valued; (3) Their use does not diminish others; (4) Their opposite is negative; (5) They manifest at cognitive, emotional and behavioral levels; (6) They are distinct from other positive traits; (7) They are embodied in consensual paragons; (8) They are found in prodigies; (9) They may be absent in some people; (10) They are desired and cultivated by different cultures. To be included in this classification, a strength must meet most of these criteria. However, each criterion taken individually is not a necessary or sufficient condition for the strength to be included. On this basis, Seligman and Peterson determined 24 character strengths, which were then theoretically grouped by content into six main virtues: wisdom, justice, courage, temperance, humanity, and transcendence (see Table 1).

To assess character strengths, the Values In Action Inventory of Strengths (VIA-IS) was developed by Peterson and Seligman (2004). It consists of 240 items measuring the respondent's endorsement of different character strengths (e.g., "I never quit a task before it is done") on a five-point Likert scale ranging from 1-"very much unlike me" to 5-"very much like me". This measurement instrument ranks the participants' strengths, and allows the identification of his or her five "signature strengths," which are considered to best reflect his or her character (Peterson and Seligman 2004). A series of research studies recently led to updated versions of the VIA-IS (McGrath 2017). The VIA-120 and VIA-72 are shortened versions of the VIA-IS, which were obtained by respectively taking the five and three items from each scale demonstrating the highest item-total correlations. Reliability studies conducted on the VIA-IS indicate Cronbach's alpha estimates ranging from .75 to .90 , while the shortened scales present estimates ranging from .67 to .90 (VIA-120) and .60 to .87 (VIA-72). The VIA-IS-R, a revised measure of the VIA, is a 192-item instrument including positively and negatively keyed items. Shorter versions, called VIA-IS-M and VIA-IS-P, are 96-items versions using four items for each strength scale selected on the basis of corrected item-total correlations. The VIA-IS-M includes positively and negatively keyed items, while the VIA-ISP only includes positively keyed items. Reliability studies conducted on the VIA-IS-R indicate Cronbach's alpha estimates ranging from .76 to .91, while shortened scales present estimates ranging from .62 to .85 (VIA-IS-M) and .62 to .87 (VIA-IS-P). Additional instruments, namely the Global Assessment of Character Strengths (72 items [long 
version] and 24 items [short version]), the Signature Strengths Survey, and the Overuse, Underuse and Optimal-Use have also been developed by the VIA Institute on Character for specific uses. Although Peterson and Seligman's conceptualization of strengths contains six virtues, early factor analysis suggested only four to five factors that partly overlapped with their model (Littman-Ovadia and Lavy 2012; McGrath 2014; Peterson et al. 2008; Ruch et al. 2010). Moreover, recent studies conducted on very large datasets measuring character strengths $(n=1,082,230)$ suggest that three main virtues emerge from this classification: caring, inquisitiveness, and self-control (McGrath et al. 2018). Nevertheless, other scholars also argue that studying intercorrelations between strengths might not be the best way to arrive at virtues, claiming that the VIA classification was never intended as a factor-analytic model, and may be examined through other means such as expert judgements of strengths and virtues (Ruch and Proyer 2015).

A third school of thought was developed at the Center of Applied Positive Psychology (CAPP) founded by Alex Linley. This approach defines strengths as a "pre-existing capacity for a particular way of behaving, thinking, or feeling that is authentic and energizing to the user, and enables optimal functioning, development and performance" (Linley 2008, p. 9). Five fundamental principles underlie this perspective: (1) The strengths approach focuses on what works in the human being; (2) Strengths are a part of human nature, everyone possesses some; (3) The individual's area of greatest potential for development lies in his/her strengths; (4) Success is attained by fixing weaknesses only when making the most of strengths as well; (5) Focusing on the individual's strengths is the smallest thing to do to make the biggest difference. The ability to draw upon strengths depends on the individual's strengths knowledge and use, and is linked to their social environment, values and interests. Therefore, strengths have great potential for development.

Linley and Harrington (2006) offer a less restrictive assessment of strengths. This perspective acknowledges that defining strengths through inclusion and exclusion criteria may indeed provide a framework, but considers this very structure to potentially be restrictive. Individuals exhibit strengths daily, and evidence of individual strengths can be collected as data (Linley 2008). For example, feeling energized in an activity, feeling a sense of authenticity, learning new information quickly, losing track of time or regularly meeting success in an activity are signs of the presence of a strength. Linley et al. (2010a, b) also developed the Realise2, now called the Strengths Profile, which evaluates 60 strengths across three dimensions: energy, performance, and frequency of use. It is comprised of 180 statements representing each of the 60 strengths (e.g., "Building rapport with people quickly and easily"; "Competing against others"; "Supporting others to grow and develop their abilities") which are measured according to the three dimensions of energy, performance, and use on specific seven-point Likert-type scales (e.g., "how do you feel when..." from 1-"very drained" to 7-"very energized"; "how successful are you at..." from 1-"very unsuccessful" to 7-"very successful"; "how often do you find yourself..." from 1-"extremely rarely" to 7-“extremely often"). The Strengths Profile report provides results by classifying the attributes in four distinct categories: realised strengths, unrealised strengths, learned behaviors, and weaknesses. Available data indicates adequate psychometric qualities, including internal consistency and test-retest reliability (Linley and Dovey 2015). In a pilot study testing over 100 working adults, Cronbach's alpha values ranged from .68 to .90. In a sample of 132 individuals, test-retest reliability over a 1-week period was calculated for each element (performance, use and energy) for each of the 60 strengths, and correlations ranged between $r=.63$ and $r=.80$. Although no studies on factorial structure are available for this instrument, strengths were clustered on a conceptual basis under five categories labeled Being, Communicating, Motivating, Relating and Thinking. 
In sum, three main schools of thought have developed models for conceptualizing, assessing, and applying strengths in the workplace. While these movements are to some extent distinct in the way they define and provide classifications of strengths, important similarities remain as they mutually influenced each other. Indeed, most experts acknowledge that strengths are naturally present within individuals, tend to generate energy, and drive performance. Furthermore, strengths are considered as positive attributes that are stable, but not fixed and can be developed with conscious effort. Therefore, as numerous studies have been conducted on this subject in recent years, especially in the workplace, providing a thorough portrait of the scientific knowledge available seems imperative in order to capture the actual understanding in the field and guide future research and application.

\section{Method}

As mentioned above, this article has a twofold purpose: (1) to provide a summary of the outcomes of strengths use in organizations, and (2) to present the main intervention steps found in the literature regarding strengths development in the workplace, and propose an integrative model. To meet the first objective, a systematic review was conducted and the available scientific literature was thoroughly examined. To meet the second objective, a narrative literature review was conducted and the main intervention models found in articles, book chapters and professional books were reviewed.

The systematic review was conducted using different databases. First, peer-reviewed articles were searched through the PsychINFO and PsychARTICLES databases and by using the Google Scholar search engine. Keywords searched included: strengths, work, organization, job, and workplace. This preliminary step identified 136 articles via PsychINFO and PsychARTICLES and 462 articles via Google Scholar. The initial search targeted articles that met the following inclusion criteria: (a) published in a peer-reviewed journal; (b) written in English; (c) published after 1998, when the field of positive psychology was established; (d) used a quantitative approach. Exclusion criteria were articles that (a) focused on strengths possession or endorsement; (b) focused on a single strength (e.g., gratitude, optimism); (c) involved unemployed participants (e.g., students, job seekers, voluntary work); (d) used a qualitative approach; and (e) narrative literature reviews, thesis, case reports or conference presentations. Twenty-five articles were selected and are listed in the table below (see Table 2).

To meet the second objective, a narrative literature review was carried out. First, all scientific articles that presented one or more interventions in strength development at work were consulted. Second, key books and chapters on strength development at work that fall into one of the three schools of thought mentioned above, either in terms of the definition of strengths or one of the classifications, were consulted and thoroughly examined.

\section{Results and Discussion-Consequences of Strengths Use}

First, results of the systematic review of the literature on strengths use at work will be presented. To this end, the 27 studies selected according to our criteria will be described and discussed. 


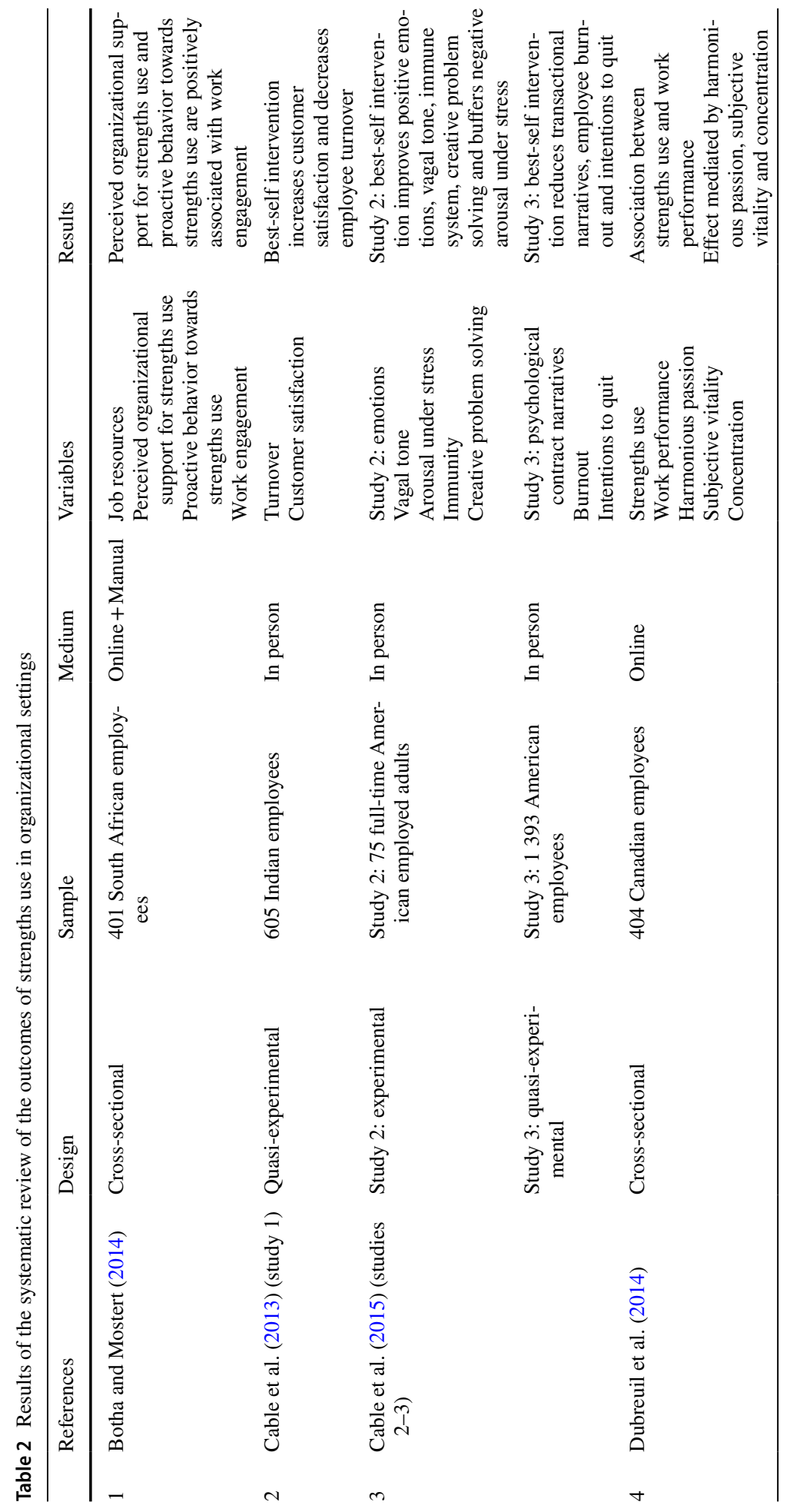




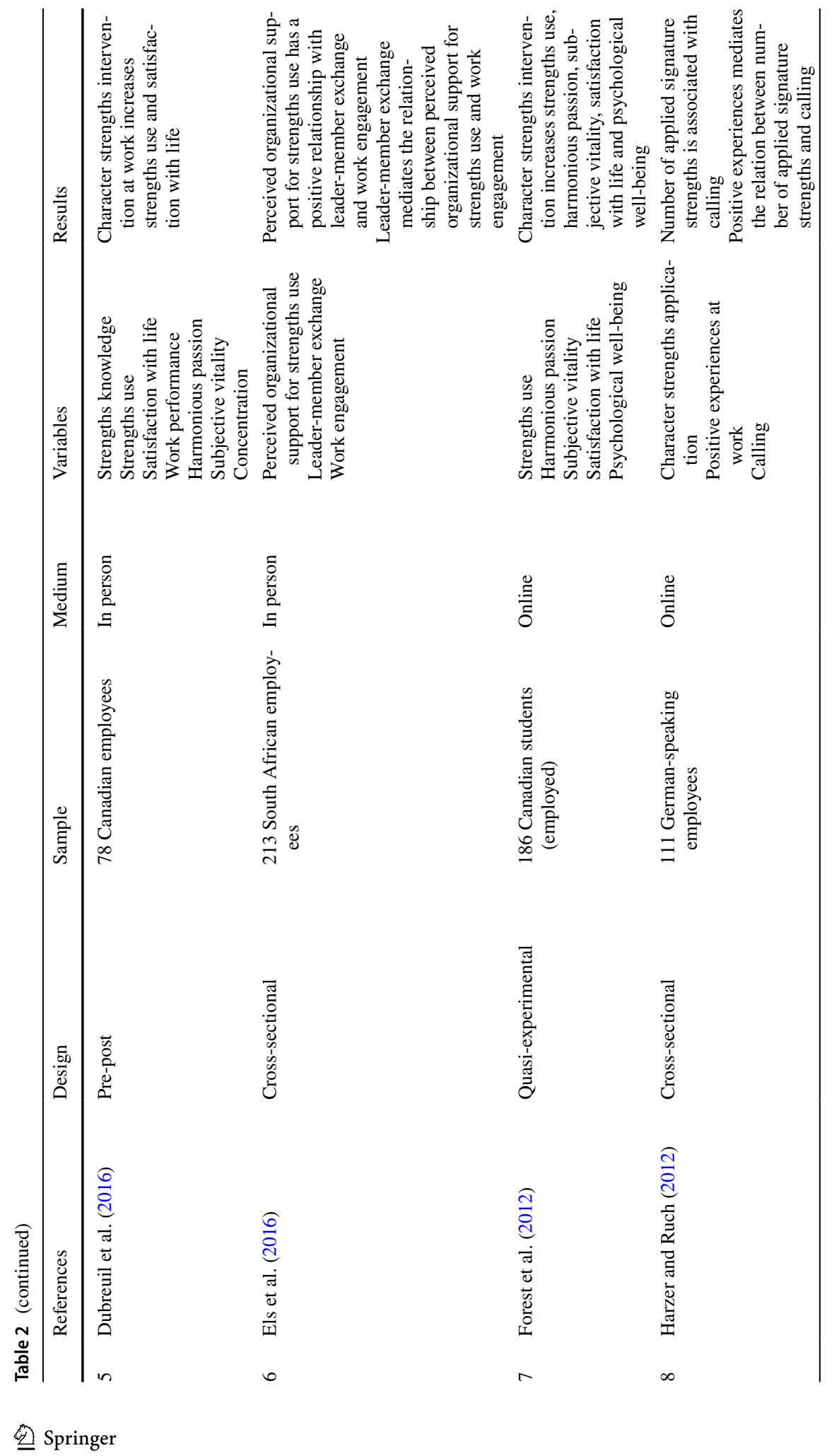




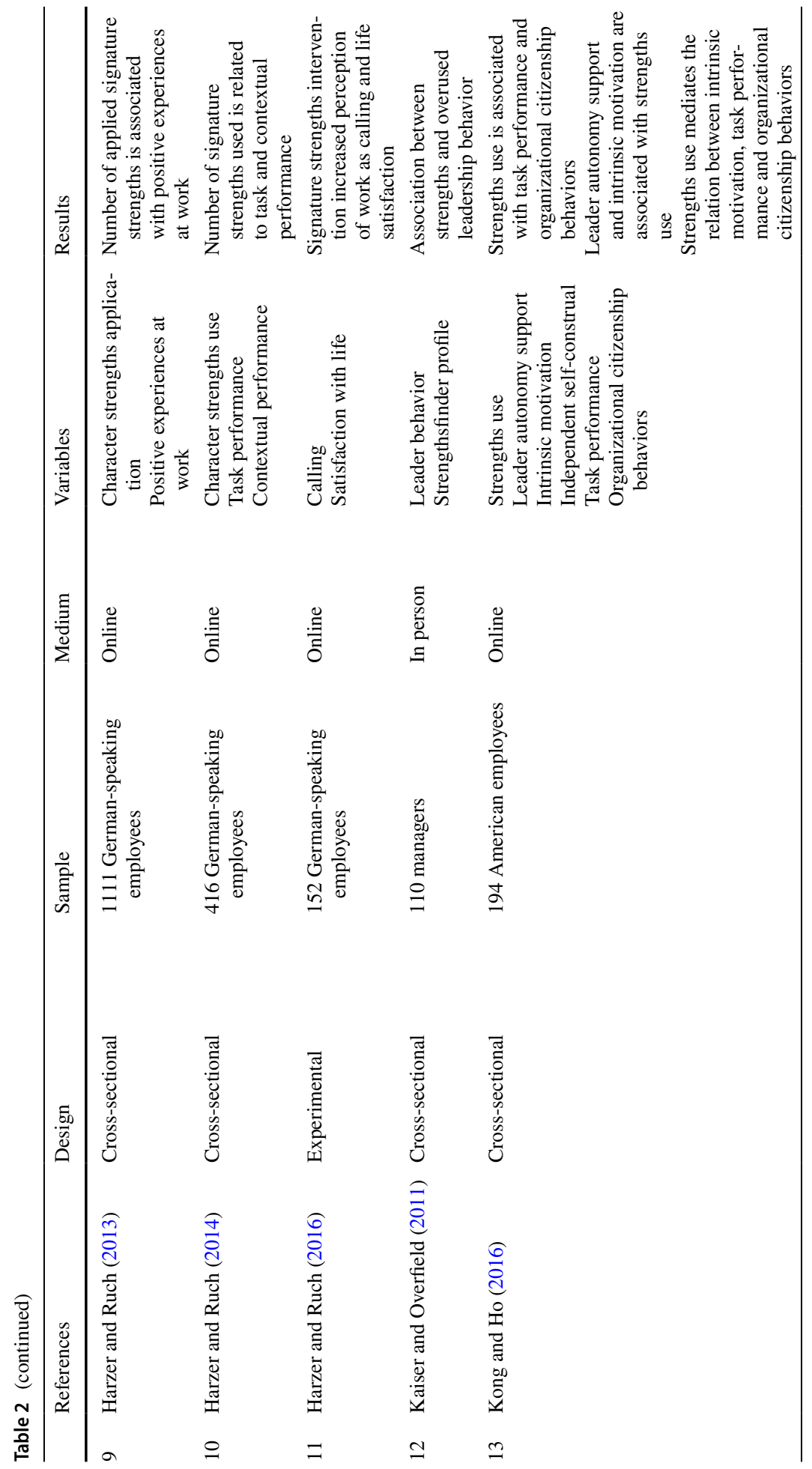




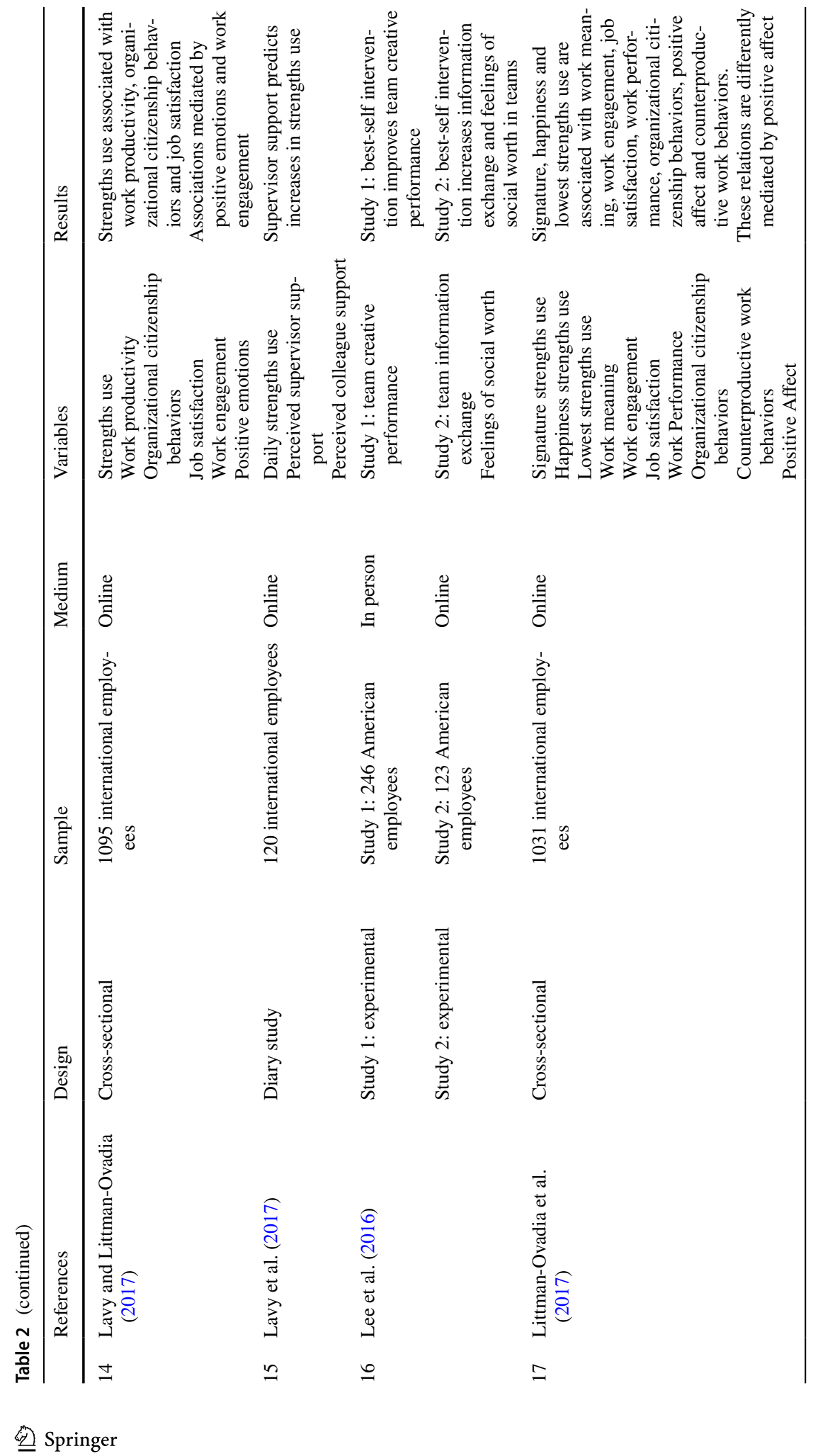




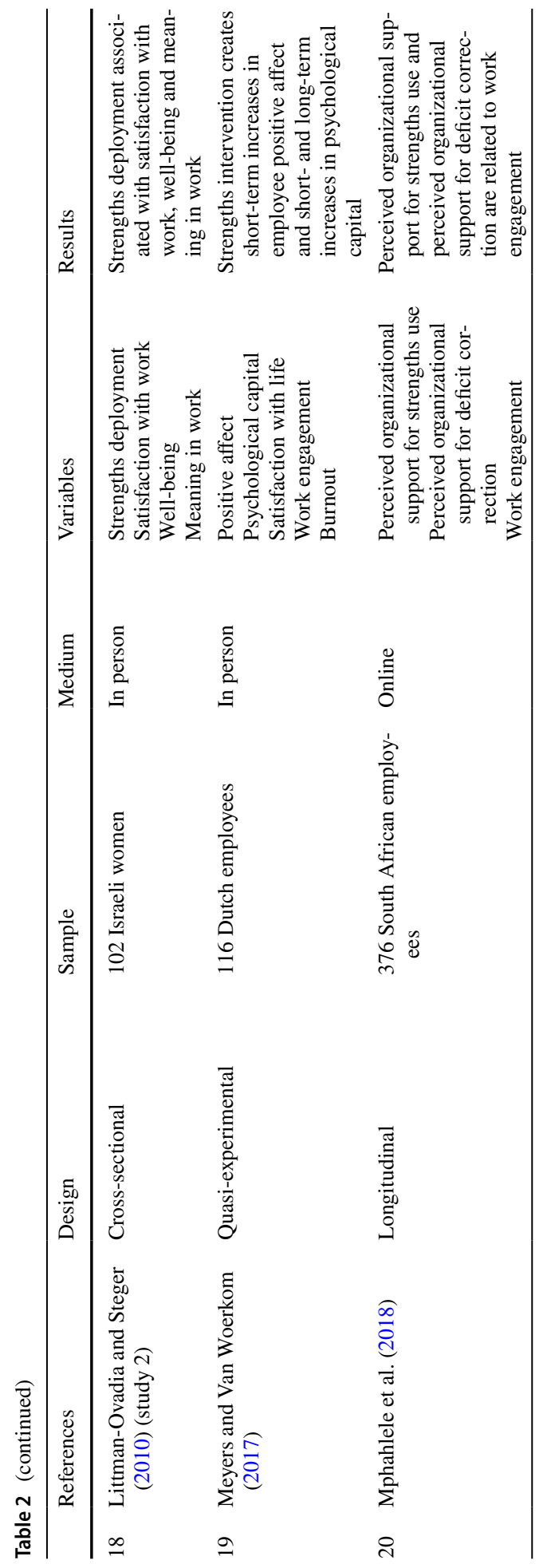




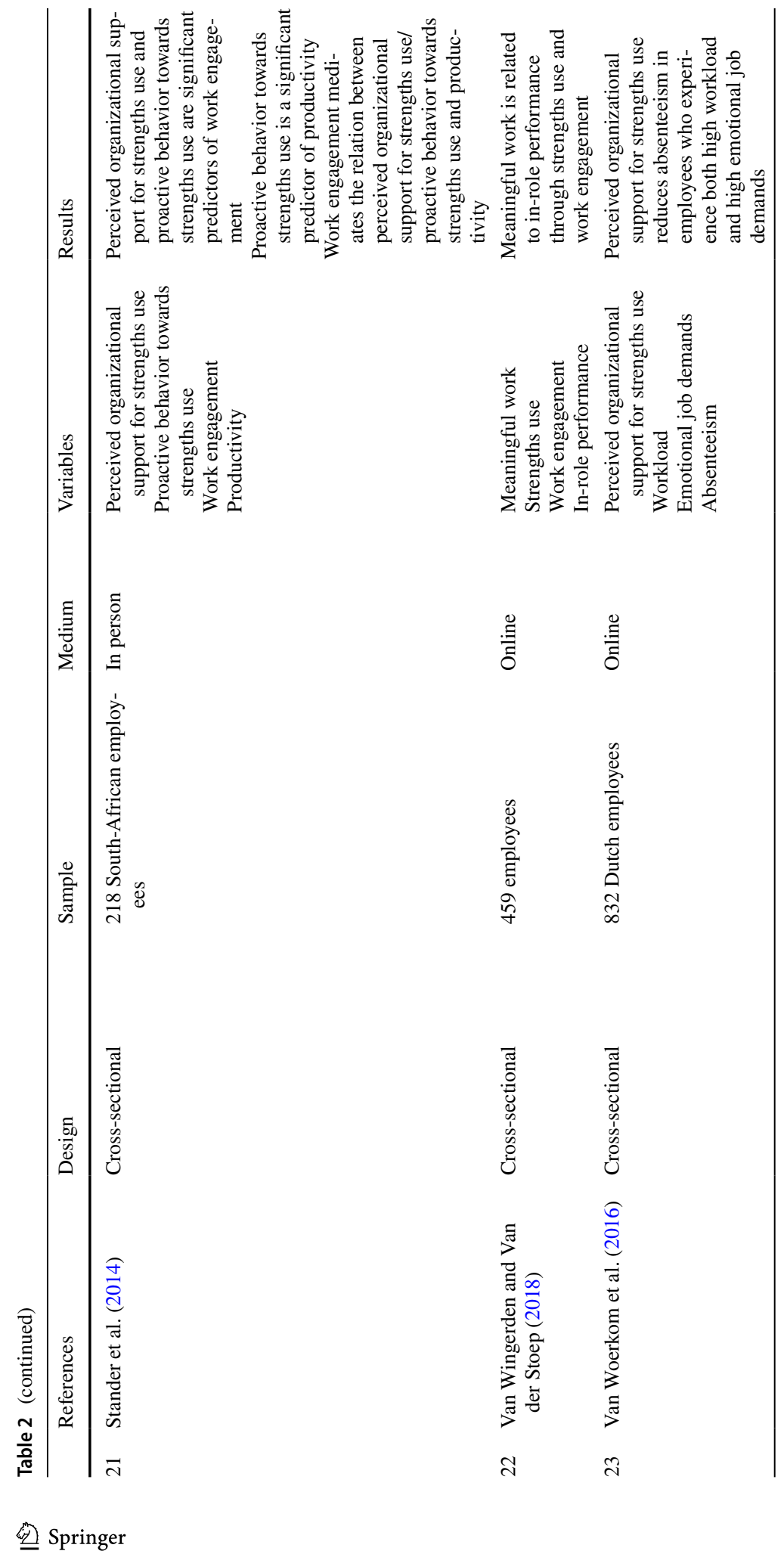




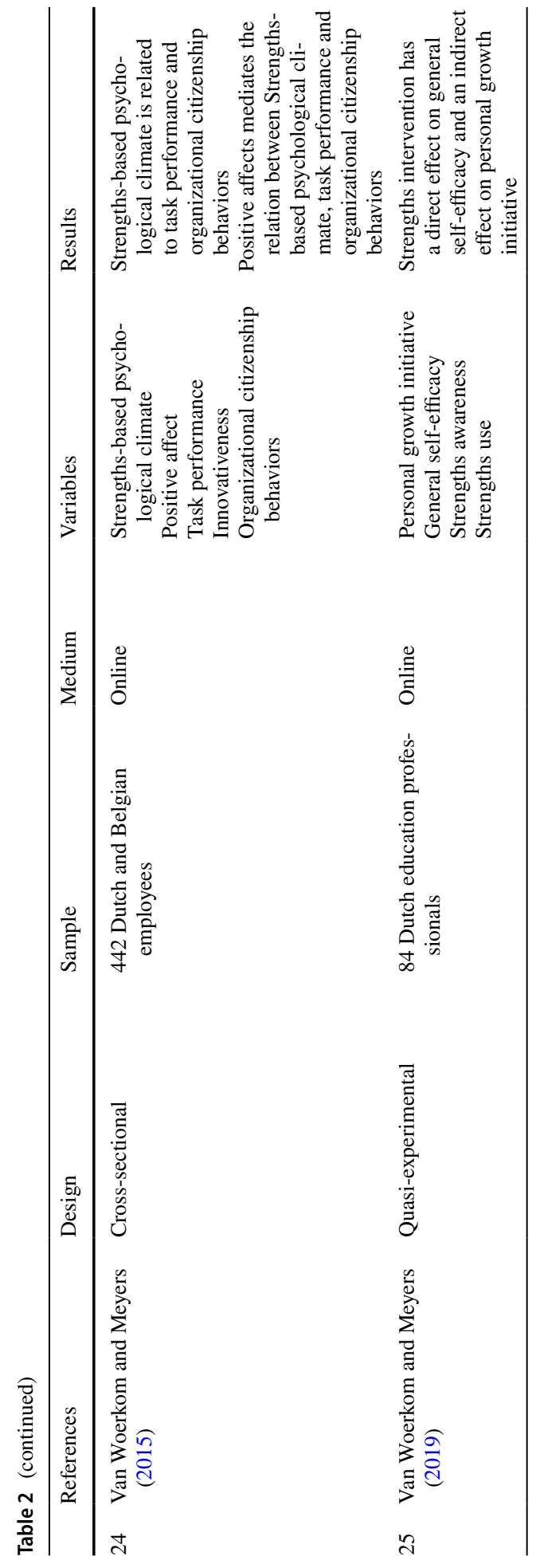




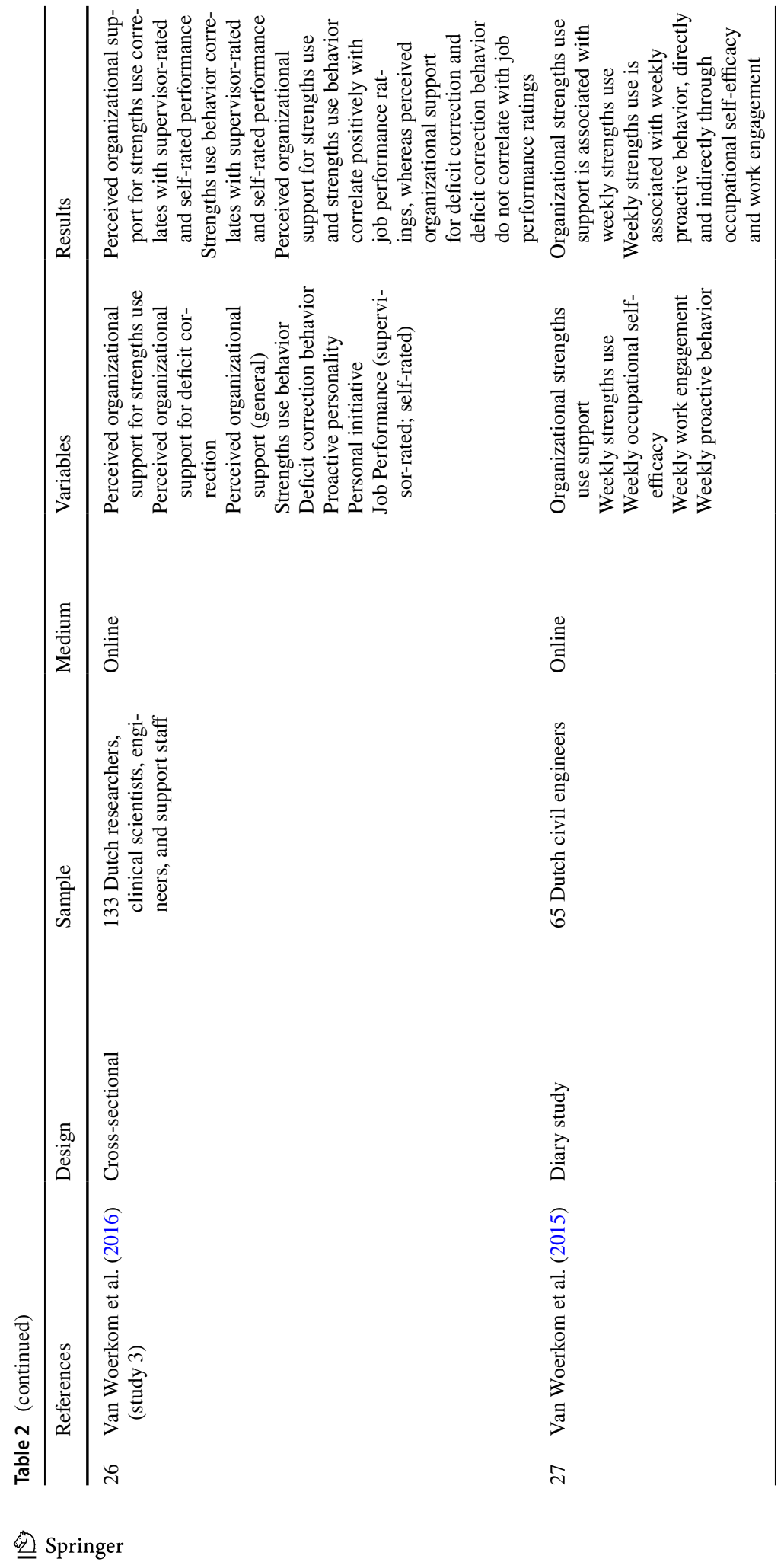




\subsection{Results}

The results of the 27 studies included are presented in Table 2. Overall, strengths use and development seems to be positively associated with work performance and job satisfaction. Indeed, results indicate that when employees identify, use, and develop their strengths at work, they tend to perform better and are more proactive in the workplace (Cable et al. 2013; Dubreuil et al. 2014; Harzer and Ruch 2014; Van Wingerden and Van der Stoep 2018; Van Woerkom et al. 2015), demonstrating more helping behaviors and less counterproductive ones (Kong and Ho 2016; Lavy and Littman-Ovadia 2017; Littman-Ovadia et al. 2017), finding more creative solutions to problems (Lee et al. 2016) as well as adapting to change better (Dubreuil et al. 2014). Additionally, results suggest that these relations are often mediated by positive emotions and engagement (Lavy and Littman-Ovadia 2017; Littman-Ovadia et al. 2017; Van Woerkom and Meyers 2015). In contrast, over- or underutilization of strengths seems counterproductive and detrimental to performance (Harzer and Ruch 2012; Kaiser and Overfield 2011).

Results also indicate that strengths use and development tends to be associated with increased satisfaction and well-being at work. Strengths use is generally associated to a sense of meaning at work (Harzer and Ruch 2013; Littman-Ovadia et al. 2017; LittmanOvadia and Steger 2010), and some studies suggest that strengths identification and development could encourage work to be perceived as a vocation (Harzer and Ruch 2016). In addition, strengths use in the workplace is also generally related to positive experiences, such as satisfaction, pleasure, and commitment (Harzer and Ruch 2013), as well as to positive emotions such as joy, pride or enthusiasm (Cable et al. 2015; Littman-Ovadia et al. 2017), which in turn may have a positive impact on well-being (Meyers and Van Woerkom 2017). Strengths identification, use, and development in the workplace also tends to promote work engagement (Cable et al. 2015; Littman-Ovadia et al. 2017; Van Wingerden and Van der Stoep 2018; Van Woerkom et al. 2015), psychological well-being (Forest et al. 2012), and life satisfaction (Dubreuil et al. 2016).

In a broader perspective, our review also indicated that organizational support for strengths use appears to have an important impact on different work outcomes. As such, a strengths-based psychological climate seems to be associated with a greater reliance on personal strengths (Stander et al. 2014; Van Woerkom et al. 2016a), especially when managers promote employees' autonomy (Kong and Ho 2016). Such an environment can positively affect work engagement (Botha and Mostert 2014; Mphahlele et al. 2018) and encourage positive interactions between coworkers (Lee et al. 2016), leaders, and subordinates (Els et al. 2016). Organizational support for strengths use is also positively associated with in-role and extra-role performance (Van Woerkom and Meyers 2015; Van Woerkom et al. 2016b), as well as with lower absenteeism, especially when employees are confronted with high workload and emotional demands (Van Woerkom et al. 2016a).

\section{Discussion}

The results of this systematic review tend to corroborate the fundamental claim that strengths use and development are closely linked to work performance and well-being (Buckingham and Clifton 2001; Linley and Harrington 2006; Peterson and Seligman 2004; Roberts et al. 2005b). Furthermore, they also support major theoretical models proposing 
that strengths use produces its effects on performance and well-being mainly through heightened feelings of vitality, authenticity, and competence (Linley 2008; Peterson and Seligman 2004; Hodges and Clifton 2004). Indeed, it seems that people who regularly use their strengths at work are more engaged and absorbed in their tasks (Dubreuil et al. 2014; Harzer and Ruch 2012, 2013; Lavy and Littman-Ovadia 2017; Littman-Ovadia et al. 2017), and tend to feel more effective and intrinsically motivated at work (Clifton and Harter 2003; Dubreuil et al. 2014; Kong and Ho 2016; Harzer and Ruch 2014; Van Woerkom et al. 2015).

Interestingly, these positive states seem to be necessary for proactive behaviors to persist (Fritz and Sonnentag 2007), and make it possible to exceed job requirements (Frese et al. 1997). This phenomenon can be linked to Fredrickson's (2001) broaden-and-build theory, which stipulates that positive emotions broaden people's modes of thinking and action, which in turn build their personal and social resources and allow them to better adapt to change, display proactive behaviors and succeed in a variety of situations. In a similar way, self-determination theory proponents would argue that strengths use, through enhanced feelings of competency, autonomy, and relatedness, tends to foster intrinsic motivation at work (Gagné and Deci 2005; Linley et al. 2010a, b; Ryan and Deci 2000), which in turn leads to higher levels of well-being (Gagné et al. 2015) and performance (Cerasoli et al. 2014). The use and development of strengths can also be seen as promoting a growth mindset, which is described by Dweck as seeing intelligence as "a malleable quantity that can be increased with effort and learning" (Dweck et al. 2014, p. 5). This incremental conception of intelligence implies believing in the individual's learning abilities (Dweck 2006). On the one hand, for the individual believing in his/her capacities, progress involves efforts. On the other hand, for the supervisor, it implies to believe in the person's capacity of progress, and that he/she will send feedback, encouragement and seek solutions to help the person gain ground. A growth mindset is positively linked to a healthier attitude toward practice and learning, hunger for feedback, a greater ability to deal with setbacks, and improved performance over time (Blackwell et al. 2007; Dweck et al. 2014). Thus, by emphasizing a growth-mindset through strengths development, individuals can build resilience and long-term achievement (Dweck 2010). Without a doubt, working on strengths is about identifying these resources and learning to make the most of them in consideration with situational demands. Moreover, strengths use can be positioned in Job Demands-Resources theory (Bakker and Demerouti 2017) as one of the behaviors that mediates the feedback-loop from work engagement to job and personal resources. Accordingly, employees who are engaged in their work are motivated to stay engaged. One of the ways to realize this sustained work engagement is by proactively using one's character strengths because using strengths facilitates personal resources like optimism and self-efficacy (Bakker and Van Woerkom 2017). Another possibility is to engage in job crafting (i.e. proactively optimizing one's job demands and resources; Tims et al. 2016) so as to make strengths use more likely (Kooij et al. 2017). Thus, strengths use also has a positive influence on job resources, and may play a crucial role in the motivational gain cycle proposed by JD-R theory.

These findings also echo studies conducted on strengths use and development in other settings. In academic contexts, previous research has shown that relying on personal strengths tends to improve students' well-being and academic performance, as well as effectiveness, autonomy and motivation (Madden et al. 2011; Waters 2011; Weber et al. 2016). Similarly, clinical findings show that well-being and optimal human functioning can be promoted through strengths use (Rashid 2009; Rashid and Anjum 2008; Rashid et al. 2017; Seligman et al. 2006). Rashid (2015) argues that positive psychotherapies, and more 
specifically strengths-focused ones, tend to decrease depression and increase life satisfaction, hope and good social functioning, as well as well-being.

\section{Results and Discussion-Strengths Interventions}

Having reviewed findings on the outcomes of strengths use at work, the various interventions used to develop strengths in the workplace will be presented and discussed, and an integrative model will be proposed.

\subsection{Results}

The main intervention models used in organizational contexts draw upon a variety of methods for identifying, using and developing individual strengths. For example, Harzer and Ruch (2016) recently developed an online intervention protocol which was applied and tested against a placebo control condition. Participants first identified their four highest character strengths (using the VIA-Survey), and were requested to reflect on how they used them in their daily activities and tasks. They were then asked to use their four main strengths in new and different ways at work for 4 weeks, and were encouraged to do so by developing "if-then" plans. After 1 month, results indicated an increase in calling and life satisfaction. These results were maintained up to 6 months afterwards. In a similar way, Forest et al. (2012) also developed an intervention in which they asked employees to identify their main character strengths (using the VIA-Survey), to describe themselves (on a printed form) when they are at their best at work, and then to use two of their strengths at work in a new way over the course of 2 weeks. At the end of this period, participants were asked to indicate which strengths they used, and to think about the positive consequences of using these strengths in their current job. Two months later, the results showed improved strengths use, as well as increases in well-being and harmonious passion.

In their field study conducted with a sample of 116 Dutch employees, Meyers and Van Woerkom (2017) described three stages in their experimental protocol: (1) identification of strengths; (2) development of strengths; and (3) strengths use. Participants were first asked to identify their three dominant strengths using specially developed character strengths cards and guiding questions. Then, they took part in a half-day training program that was facilitated by professionals and designed to help them develop and use their strengths at work. Each participant then had to choose a partner who would check on their progress regarding their strengths use and development. Results showed a short-term increase in employee positive affect, which returned to baseline 1 month after the intervention, as well as a short-term increase in psychological capital (self-efficacy, optimism, hope, resilience), which was maintained over the 1-month follow-up period.

In their general model of strengths development, Clifton and Harter (2003) suggest three steps that differ slightly from those mentioned above: (1) identification, (2) integration, and (3) changed behaviors. The distinctive feature of this model is that according to these authors, any strength intervention must include an integration step, which can vary from a few hours to a few weeks, in order to help the individual acknowledge this new information about him- or herself, gain a deeper awareness of his/her strengths and integrate it into his/her view of self before planning strengths development and use. Based on this approach, Dubreuil et al. (2016) proposed a three-step intervention program (identification, integration, action) which was applied in the workplace using a 
sample of 78 participants. In this study, participants were first asked to identify their strengths using the VIA-Survey. The researcher then facilitated a 3-h, on-site training period. In the first part of the training, participants were asked to discuss their strengths and how they contribute to their past and present success (integration). In the second part of the training, participants were asked to plan with their peers, through specific questions, how they could make better use of their strengths in their current work (action). Three months after the intervention, results indicated a significant increase in strengths use compared to baseline. However, as there was no control group in this particular study, a possible placebo effect cannot be ruled out.

In a similar fashion and building on their previous work, Van Woerkom and Meyers (2019) recently conducted a second field experiment with a sample of 84 education professionals. Their study involved a quasi-experimental design with 1-month pretest and 1-month post-test measures of general self-efficacy, personal growth initiative, strengths awareness and strengths use. The intervention protocol consisted of two specific workshops separated by a 4-week interval. Prior to the first workshop, participants were asked to complete the Strengthsfinder assessment. The first workshop was focused on a further discovery of personal strengths (using open-ended questions and discussion approaches) and on the development of a personal plan regarding strengths use in the workplace. Participants were asked to share their plans with their colleagues in order to increase commitment. The second workshop, conducted 4 weeks later, was specifically aimed at following up and building on initial engagements. After sharing and discussing about the implementation of personal plans, participants were introduced to the concept of jobcrafting and asked, following a short task analysis exercise, to develop a second personal plan in which they would try to align part of their jobs with their strengths. Results indicated that the intervention had a direct effect on general self-efficacy and an indirect effect on personal growth initiative. Furthermore, results revealed that participants with low to medium initial levels of general self-efficacy benefited the most from the intervention.

Adopting a different approach, the Reflected Best Self is a specific strengths development exercise which was established by a group of researchers to openly identify and develop strengths based on feedback received from peers (Roberts et al. 2005b). This description of oneself when one is at one's best is based on colleagues' and relatives' feedback, which the subject collects and thoroughly analyzes. The person then produces a specific synthesis of his/her main strengths, and develops an action plan to optimize their use in connection with professional objectives. This exercise is particularly useful in coaching, where the individual has the necessary time, energy, and personal commitment to devote to this deep reflection (Roberts et al. 2005b).

Finally, Linley (2008) also describes general intervention steps to develop leaders' strengths use. Leaders can put the following seven elements into practice: (1) knowing and accepting their own strengths and weaknesses; (2) knowing their team members' strengths and weaknesses and respecting them whatever they may be; (3) allocating tasks to the person with the most appropriate strengths; (4) giving positive feedback; (5) genuinely and appropriately disclosing weaknesses to enable acceptance and progress; (6) calibrating strengths correctly according to the situation and according to the "golden mean" principle (the right strength, to the right amount, in the right situation); (7) recognizing his/her role as an organizational climate engineer.

Hence, a range of different approaches to strengths development exists. Whether on an individual, group or organizational level, strengths-based interventions can be an opportunity to develop potential in an innovative way. 


\subsection{Additional Considerations}

Currently, most research mainly focuses on the presence and possession of strengths rather than their use and development (Wood et al. 2011). However, instead of seeing strengths as isolated and stable personality traits, it is important that practitioners view them as evolving characteristics that must be carefully brought to attention and then correctly developed (Biswas-Diener et al. 2011). While mere strengths identification without further development may only have short-term effects on the individuals (Dubreuil et al. 2016; Meyers et al. 2015; Seligman et al. 2005), we also know that overusing or underusing a strength can be detrimental to performance (Kaplan and Kaiser 2009). Therefore, adequate training, continuous support and feed-back in strengths development are key points that must be considered in any program (Kaplan and Kaiser 2009; Linley 2008; Linley and Harrington 2006).

Several intervention strategies are possible (Quinlan et al. 2012). For an intervention to be effective, it must be designed with care. Activities must be engaging, relevant and meaningful, while supporting behavior, habits and rituals that promote the continued use of strengths after the intervention (Dubreuil et al. 2016; Meyers et al. 2015). Moreover, the attitude of the person conducting the intervention seems to impact the consequences of the intervention (Cox 2006). Practitioners showing high adherence to strengths-based practices seem to produce better results. Creating a culture of risk taking, emphasizing challenge and not success, giving a sense of progress, and underlining efforts rather than results seems essential to build a growth mindset that leads to success (Dweck 2010).

\section{Discussion}

Considering the interventions and protocols put forward by various researchers and practitioners in the field, a five-step summary and integrative model to promote strengths development in organizational environments is proposed (Fig. 1).

The first step is to educate the participant about the strengths approach and the proposed intervention (1). This phase is critical for the employee to be able to appreciate the value of the approach, to understand the steps involved in the process, and to be actively and genuinely involved in the intervention (Clifton and Harter 2003). The approach's origins, advantages and limitations, as well as the overall process, must therefore be presented, and all questions must be answered (Dubreuil and Forest 2017). This step helps reduce negativity bias, the natural tendency of humans to give more attention to negative than positive information (Ito et al. 1998), and fully engage participants in the intervention from the start.

The second step is to identify the person's strengths (2). As discussed earlier, this can be accomplished through a psychometric instrument (e.g., StrengthsFinder, VIA-Survey,

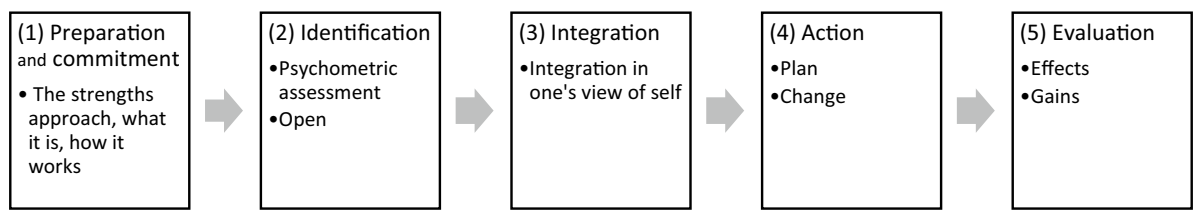

Fig. 1 Integrative model of strengths development in organizational environments 
StrengthProfile), or in a less restrictive way by observing oneself (e.g., identifying activities that involve performance, energy, authenticity and flow; Biswas-Diener et al. 2011; Linley 2008; Linley and Burns 2010), or by collecting feedback from peers (Roberts et al. 2005b). Different methods can be used according to the particular demands of the situation, and the resources available. Although each method can provide very useful information on its own, a combination of different methods (e.g., psychometric instrument and feedback from peers) can yield a more accurate and complete picture of an individual's strengths (see Dubreuil and Forest 2017, for a thorough discussion of these methods).

The third step is the integration of strengths in the individual's identity (3). This step is particularly important for ensuring the quality of the overall process, as it allows the individual to take the necessary time to fully grasp and assimilate this new information, better understand the reasons for his/her actions and observe his/her behavior in light of personal strengths. This new conceptualization of self can then be integrated into the identity before planning the next steps (Clifton and Harter 2003). It can be facilitated by appropriation exercises, such as specific questions linking strengths to previous successes (Dubreuil et al. 2016), feedback analysis (Roberts et al. 2005b), and self-portrayal exercises (Forest et al. 2012), in order to help the individual gain a deeper awareness of his/her strengths. A certain period of time, which may vary from one individual to another, is therefore necessary.

The fourth step is action (4), which consists of two sub-stages. First, the person decides the specific changes he/she wants to put in place to make better use of his/her personal strengths. The individual then implements the intended transformations. To help workers move from theory to action, strengths must be invested in specific individual, group, or organizational goals and initiatives (e.g., personal objectives, team projects, new tasks and responsibilities, complementary partnerships, etc.), and their application must be monitored or closely followed by managers, peers or coaches, who can provide support and encourage progress (Linley 2008). In the long term, it is important that the person always remain careful to avoid the overuse of strengths, and rather aims to use the right strength, to the right amount, and at the right time (Biswas-Diener et al. 2011; Kaplan and Kaiser 2009; Kaiser and Overfield 2011).

Finally, the fifth step is evaluation (5). At the end of the intervention, results can be evaluated subjectively through the individual's appreciation of the progress made (in terms of strengths awareness and use, goal achievement, overall well-being, etc.), or objectively through changes in various variables that were measured prior to the intervention: wellbeing, job satisfaction, motivation, work engagement, or job performance. A measure of the impact of the intervention can then make it possible to ensure the effectiveness of the procedure and allow for readjustment if necessary.

\section{General Discussion}

The present study aimed to provide a literature review on strengths use and development in the workplace. The outcomes of strengths use in an organizational context were first summarized, a narrative literature review of the main strengths interventions was conducted, and an integrative model for strengths development was proposed. As we have seen, strengths use in the workplace is associated to various employee well-being and work performance outcomes. Additionally, strengths development studies and intervention models use similar methods, which can be integrated into a general model encompassing five overarching steps. These findings and propositions can be very useful for researchers 
and professionals, as they indicate that strengths use and development in the workplace has the potential to foster well-being as well as performance, a need that is expressed in organizations worldwide. Researchers are therefore invited to refine and develop the actual knowledge in the field, while professionals are encouraged to identify, use, and optimize employee strengths in organizations, through improved human resources management practices.

\subsection{Limitations}

Some limitations regarding our review of strength use and development in organizations must be underlined. First, as this is a recent approach, there is still a great need for further theory and research in the area before one can propose any definitive conclusions. The number of studies on strengths use in organizational settings is still modest, our review of the literature presenting only 27 studies on the outcomes of strengths use at work. In addition, these studies mainly focus on European and North American populations, which constitute a cultural bias that must be taken into consideration in the generalization of the results to other continents.

The second limitation relates to the use of self-assessment measures for all variables in most studies, which may inflate the relationships between variables due to commonvariance bias (Podsakoff et al. 2012). Furthermore, as many studies used self-reported measures of work performance (with a few exceptions, e.g. Harzer and Ruch 2012, 2014; Kaiser and Overfield 2011; Kong and Ho 2016; Van Woerkom et al. 2016b), results are also prone to social desirability bias and must be interpreted with caution. Along the same lines, it must also be acknowledged that the current lack of evidence regarding the validity of major strengths classifications instruments constitutes an important problem in this field. In fact, results of complete and thorough factor analyses are only available for one instrument, namely the VIA Survey.

Finally, although several studies included in our review used longitudinal designs, which increases the grip on causality, an important limitation is that most studies employed a cross-sectional design. Moreover, only experimental research-for example in the form of interventions in which individuals learn to identify and use their strengths - can establish causal relations between the variables.

\subsection{Future Research Directions}

Research should continue investigating the effects of strengths use in the workplace, but also turn its attention towards the development of strength interventions, as well as the conditions that foster and enable strengths use. Since studies to date have been mainly crosssectional, it first seems imperative to further study the outcomes of strengths use and development over time. Longitudinal studies, especially experimental field studies, would yield more accurate conclusions about the expected outcomes of strengths use, such as wellbeing, performance, and work engagement, as well as about effective strengths development interventions. In this regard, structured processes such as Intervention Mapping could be utilized to support the development of interventions. This model provides a rigorous framework and protocol guiding the development of theory and evidence-based interventions through specifically designed steps (Bartholomew et al. 1998; Kok et al. 2004). The antecedents and conditions necessary for strengths use and development (such as autonomy, supervisor support and job design) would also need to be further explored in order 
to expand our knowledge beyond the mere outcomes of strengths. Finally, future research should strive to use objective measures of work performance (e.g., supervisor-rated, performance data, etc.) in order to minimize any bias relating to this particular variable.

\section{Conclusion}

Focusing on strengths presents a rare opportunity to work with people in a way that enhances their sense of identity and personal worth, while improving their well-being and their performance (Linley and Harrington 2006). The different types of interventions developed to promote these qualities may offer public and private sector organizations a significant advantage. Indeed, today's organizations need highly engaged employees, who take initiatives to perform in this uncertain economic environment, in which ever increasing competition and technological innovation are the norm (Bakker and Van Woerkom 2017; Bakker and Schaufeli 2008; Rosa 2013). Could strengths be a key to this new puzzle?

\section{References}

Asplund, J., Agrawal, S., Hodges, T., Harter, J., \& Lopez, S. J. (2014). The Clifton StrengthsFinder ${ }^{\circledR} 2.0$ technical report: Development and validation. Washington, DC: Gallup.

Bakker, A. B., \& Demerouti, E. (2017). Job demands-resources theory: Taking stock and looking forward. Journal of Occupational Health Psychology, 22(3), 273-285.

Bakker, A. B., \& Schaufeli, W. B. (2008). Positive organizational behavior: Engaged employees in flourishing organizations. Journal of Organizational Behavior, 29(2), 147-154.

Bakker, A. B., \& Van Woerkom, M. (2017). Strengths use in organizations: A positive approach of occupational health. Canadian Psychology. https://doi.org/10.1037/cap0000120.

Bartholomew, L. K., Parcel, G. S., \& Kok, G. (1998). Intervention mapping: A process for developing theory and evidence-based health education programs. Health Education \& Behavior, 25(5), 545-563.

Biswas-Diener, R. (2006). From the equator to the North Pole: A study of character strengths. Journal of Happiness Studies, 7(3), 293-310.

Biswas-Diener, R., Kashdan, T. B., \& Minhas, G. (2011). A dynamic approach to psychological strength development and intervention. The Journal of Positive Psychology, 6(2), 106-118.

Blackwell, L. S., Trzesniewski, K. H., \& Dweck, C. S. (2007). Implicit theories of intelligence predict achievement across an adolescent transition: A longitudinal study and an intervention. Child Development, 78(1), 246-263.

Botha, C., \& Mostert, K. (2014). A structural model of job resources, organizational and individual strengths use and work engagement. SA Journal of Industrial Psychology, 40(1), 1-11. https://doi. org/10.4102/sajip.v40i1.1135.

Bouskila-Yam, O., \& Kluger, A. N. (2011). Strength-based performance appraisal and goal setting. Human Resource Management Review, 21(2), 137-147.

Buckingham, M., \& Clifton, D. O. (2001). Now, discover your strengths. New York, NY: Free Press.

Cable, D., Lee, J. J., Gino, F., \& Staats, B. R. (2015). How best-self activation influences emotions, physiology and employment relationships. Harvard Business School NOM Unit Working Paper, (16-029).

Cable, D. M., Gino, F., \& Staats, B. R. (2013). Breaking them in or eliciting their best? Reframing socialization around newcomers' authentic self-expression. Administrative Science Quarterly, 58(1), 1-36.

Cerasoli, C. P., Nicklin, J. M., \& Ford, M. T. (2014). Intrinsic motivation and extrinsic incentives jointly predict performance: A 40-year meta-analysis. Psychological Bulletin, 140(4), 980-1008.

Clifton, D. O., Anderson, C. E., \& Schreiner, L. A. (2002). StrengthsQuest. Washington, DC: The Gallup Organization. Retrived from https://pdfs.semanticscholar.org/a600/58e7d3d9edf77c3f14e5ac7f0 27b4e7dffeb.pdf. Accessed 6 July 2017.

Clifton, D. O., \& Harter, J. K. (2003). Investing in Strengths. In K. S. Cameron, J. E. Dutton, \& R. E. Quinn (Eds.), Positive organizational scholarship: Foundations of a new discipline (pp. 111-121). San Francisco, CA: Berrett-Koehler Publishers Inc. 
Cox, K. F. (2006). Investigating the impact of strength-based assessment on youth with emotional or behavioral disorders. Journal of Child and Family Studies, 15(3), 278-292.

Dahlsgaard, K., Peterson, C., \& Seligman, M. E. (2005). Shared virtue: The convergence of valued human strengths across culture and history. Review of General Psychology, 9(3), 203.

Dubreuil, P., \& Forest, J. (2017). "Choose a job you love, and you will never have to work a day in your life": A strengths-based leadership approach to optimal functioning at work. In K. Kelloway, K. Nielsen, \& J. Jimoff (Eds.), Leading to occupational health and safety (pp. 281-306). Chichester: Wiley-Duckworth.

Dubreuil, P., Forest, J., \& Courcy, F. (2014). From strengths use to work performance: The role of harmonious passion, subjective vitality, and concentration. The Journal of Positive Psychology, 9(4), 335-349.

Dubreuil, P., Forest, J., Gillet, N., Fernet, C., Thibault-Landry, A., Crevier-Braud, L., et al. (2016). Facilitating well-being and performance through the development of strengths at work: Results from an intervention program. International Journal of Applied Positive Psychology, 1(1-3), 1-19.

Dweck, C. S. (2006). Mindset: The new psychology of success. New York: Random House.

Dweck, C. S. (2010). Even geniuses work hard. Educational Leadership, 68(1), 16-20.

Dweck, C. S., Walton, G. M., \& Cohen, G. L. (2014). Academic tenacity: Mindsets and skills that promote long-term learning. Retrieved from Stanford Graduate School of Education website: https://ed.stanf ord.edu/sites/default/files/manual/dweck-walton-cohen-2014.pdf. Accessed 4 Aug 2018.

Els, C., Viljoen, J., de Beer, L., \& Brand-Labuschagne, L. (2016). The mediating effect of leader-member exchange between strengths use and work engagement. Journal of Psychology in Africa, 26(1), 22-28.

Forest, J., Mageau, G. A., Crevier-Braud, L., Bergeron, É., Dubreuil, P., \& Lavigne, G. L. (2012). Harmonious passion as an explanation of the relation between signature strengths' use and well-being at work: Test of an intervention program. Human Relations, 65(9), 1233-1252.

Fredrickson, B. L. (2001). The role of positive emotions in positive psychology: The broaden-and-build theory of positive emotions. American Psychologist, 56(3), 218.

Frese, M., Fay, D., Hilburger, T., Leng, K., \& Tag, A. (1997). The concept of personal initiative: Operationalization, reliability and validity in two German samples. Journal of Occupational and Organizational Psychology, 70(2), 139-161.

Fritz, C., \& Sonnentag, S. (2007). Antecedents of day-level proactive behavior: A look at job stressors and positive affect during the workday. Journal of Management, 1(35), 94-111.

Gable, S. L., \& Haidt, J. (2005). What (and why) is positive psychology? Review of General Psychology, 9(2), 103-110.

Gagné, M., \& Deci, E. L. (2005). Self-determination theory and work motivation. Journal of Organizational Behavior, 26(4), 331-362.

Gagné, M., Forest, J., Vansteenkiste, M., Crevier-Braud, L., Van den Broeck, A., Aspeli, A. K., et al. (2015). The multidimensional work motivation scale: Validation evidence in seven languages and nine countries. European Journal Of Work And Organizational Psychology, 24(2), 178-196.

Ghielen, S. T. S., van Woerkom, M., \& Christina Meyers, M. (2017). Promoting positive outcomes through strengths interventions: A literature review. The Journal of Positive Psychology, 13(6), 573-585.

Harzer, C., \& Ruch, W. (2012). When the job is a calling: The role of applying one's signature strengths at work. The Journal of Positive Psychology, 7(5), 362-371.

Harzer, C., \& Ruch, W. (2013). The application of signature character strengths and positive experiences at work. Journal of Happiness Studies, 14(3), 965-983.

Harzer, C., \& Ruch, W. (2014). The role of character strengths for task performance, job dedication, interpersonal facilitation, and organizational support. Human Performance, 27(3), 183-205.

Harzer, C., \& Ruch, W. (2016). Your strengths are calling: Preliminary results of a web-based strengths intervention to increase calling. Journal of Happiness Studies, 17(6), 2237-2256.

Hodges, T. D., \& Asplund, J. (2010). Strengths development in the workplace. In A. Linley, S. Harrington, \& N. Garcea (Eds.), Oxford handbook of positive psychology and work (pp. 213-220). New York: Oxford University Press.

Hodges, T. D., \& Clifton, D. O. (2004). Strength-based development in practice. In P. A. Linley \& S. Joseph (Eds.), International handbook of positive psychology: From research to application (pp. 256-268). New Jersey: Wiley and Sons.

Ito, T. A., Larsen, J. T., Smith, N. K., \& Cacioppo, J. T. (1998). Negative information weighs more heavily on the brain: The negativity bias in evaluative categorizations. Journal of Personality and Social Psychology, 75(4), 887.

Kaiser, R. B., \& Overfield, D. V. (2011). Strengths, strengths overused, and lopsided leadership. Consulting Psychology Journal: Practice and Research, 63(2), 89-109. 
Kaplan, R. E., \& Kaiser, R. B. (2009). Stop overdoing your strengths. Harvard Business Review, 87(2), $100-103$.

Kok, G., Schaalma, H., Ruiter, R. A. C., Van Empelen, P., \& Brug, J. (2004). Intervention mapping: Protocol for applying health psychology theory to prevention programmes. Journal of Health Psychology, 9, 85-98.

Kong, D. T., \& Ho, V. T. (2016). A self-determination perspective of strengths use at work: Examining its determinant and performance implications. The Journal of Positive Psychology, 11(1), 15-25.

Kooij, D. T. A. M., Van Woerkom, M., Wilkenloh, J., Dorenbosch, L., \& Denissen, J. J. A. (2017). Job crafting towards strengths and interests: The effects of a job crafting intervention on person-job fit and the role of age. Journal of Applied Psychology, 102(6), 971-981.

Lavy, S., \& Littman-Ovadia, H. (2017). My better self using strengths at work and work productivity, organizational citizenship behavior, and satisfaction. Journal of Career Development, 44(2), 95-109.

Lavy, S., Littman-Ovadia, H., \& Boiman-Meshita, M. (2017). The wind beneath my wings: Effects of social support on daily use of character strengths at work. Journal of Career Assessment, 25(4), $703-714$.

Lee, J. J., Gino, F., Cable, D., \& Staats, B. R. (2016). Preparing the self for team entry: How relational affirmation improves team performance. Harvard Business School NOM Unit Working Paper, (16-111).

Linley, A., \& Dovey, H. (2015). Technical manual and statistical properties for Realise2. Coventry: Centre of Applied Positive Psychology.

Linley, A., Willars, J., Biswas-Deiner, R., Garcea, N., \& Stairs, M. (2010a). The strengths book: Be confident, be successful and enjoy better relationships by realising the best of you. Coventry: Capp Press.

Linley, P. A. (2008). Average to A+. Coventry: CAPP Press.

Linley, P. A., \& Burns, G. W. (2010). Strengthspotting: Finding and developing client resources in the management of intense anger. In Happiness, healing, enhancement: Your casebook collection for applying positive psychology in therapy (pp. 1-14). Wiley.

Linley, P. A., \& Harrington, S. (2006). Strengths coaching: A potential-guided approach to coaching psychology. International Coaching Psychology Review, 1(1), 37-46.

Linley, P. A., Nielsen, K. M., Gillett, R., \& Biswas-Diener, R. (2010b). Using signature strengths in pursuit of goals: Effects on goal progress, need satisfaction, and well-being, and implications for coaching psychologists. International Coaching Psychology Review, 5(1), 6-15.

Linley, P. A., Woolston, L., \& Biswas-Diener, R. (2009). Strengths coaching with leaders. International Coaching Psychology Review, 4(1), 37-48.

Littman-Ovadia, H., \& Lavy, S. (2012). Character strengths in Israel. European Journal of Psychological Assessment, 28, 41-50.

Littman-Ovadia, H., Lavy, S., \& Boiman-Meshita, M. (2017). When theory and research collide: Examining correlates of signature strengths use at work. Journal of Happiness Studies, 18(2), 527-548.

Littman-Ovadia, H., \& Steger, M. (2010). Character strengths and well-being among volunteers and employees: Toward an integrative model. The Journal of Positive Psychology, 5(6), 419-430.

Luthans, F. (2002). The need for and meaning of positive organizational behavior. Journal of organizational behavior, 23(6), 695-706.

Madden, W., Green, S., \& Grant, A. M. (2011). A pilot study evaluating strengths-based coaching for primary school students: Enhancing engagement and hope. International Coaching Psychology Review, 6(1), 71-83.

McGrath, R. E. (2014). Scale-and item-level factor analyses on the VIA Inventory of Strengths. Assessment, 21(1), 4-14.

McGrath, R. E. (2017). Technical report: The VIA assessment suite for adults: Development and initial evaluation. Cincinnati, OH: VIA Institute on Character.

McGrath, R. E., Greenberg, M. J., \& Hall-Simmonds, A. (2018). Scarecrow, Tin Woodsman, and Cowardly Lion: The three-factor model of virtue. The Journal of Positive Psychology, 13(4), 373-392.

Meyers, M. C., \& Van Woerkom, M. (2017). Effects of a strengths intervention on general and work-related well-being: The mediating role of positive affect. Journal of Happiness Studies, 18(3), 671-689.

Meyers, M. C., Van Woerkom, M., de Reuver, R. S. M., Bakk, Z., \& Oberski, D. L. (2015). Enhancing psychological capital and personal growth initiative: Working on strengths or deficiencies. Journal of Counseling Psychology, 62(1), 50-62.

Mongrain, M., \& Anselmo-Matthews, T. (2012). Do positive psychology exercises work? A replication of Seligman et al. (2005). Journal of Clinical Psychology, 68(4), 382-389.

Mphahlele, P., Els, C., De Beer, L. T., \& Mostert, K. (2018). Investigating strengths and deficits to increase work engagement: A longitudinal study in the mining industry. SA Journal of Human Resource Management, 16, 1-16. https://doi.org/10.4102/sajhrm.v16i0.900. 
Nathan, P. E., \& Gorman, J. M. (1998). Treatments that work-and what convinces us they do. In P. Nathan \& J. Gorman (Eds.), A guide to treatments that work (pp. 3-25). New York, NY: Oxford University Press.

Park, N., Peterson, C., \& Seligman, M. E. (2006). Character strengths in fifty-four nations and the fifty US states. The Journal of Positive Psychology, 1(3), 118-129.

Peterson, C., Park, N., Pole, N., D’Andrea, W., \& Seligman, M. E. (2008). Strengths of character and posttraumatic growth. Journal of Traumatic Stress, 21, 214-217.

Peterson, C., \& Seligman, M. E. P. (2004). Character strengths and virtues: A handbook and classification. New York, NY: Oxford University Press.

Podsakoff, P. M., MacKenzie, S. B., \& Podsakoff, N. P. (2012). Sources of method bias in social science research and recommendations on how to control it. Annual Review of Psychology, 63, 539-569.

Proctor, C., Tsukayama, E., Wood, A. M., Maltby, J., Eades, J. F., \& Linley, P. A. (2011). Strengths gym: The impact of a character strengths-based intervention on the life satisfaction and well-being of adolescents. The Journal of Positive Psychology, 6(5), 377-388.

Proyer, R. T., Gander, F., Wellenzohn, S., \& Ruch, W. (2015). Strengths-based positive psychology interventions: A randomized placebo-controlled online trial on long-term effects for a signature strengthsvs. a lesser strengths-intervention. Frontiers in psychology, 6, 456.

Quinlan, D., Swain, N., \& Vella-Brodrick, D. A. (2012). Character strengths interventions: Building on what we know for improved outcomes. Journal of Happiness Studies, 13(6), 1145-1163.

Rashid, T. (2009). Positive interventions in clinical practice. Journal of Clinical Psychology, 65(5), $461-466$.

Rashid, T. (2015). Positive psychotherapy: A strength-based approach. The Journal of Positive Psychology, $10(1), 25-40$.

Rashid, T., \& Anjum, A. (2008). Positive psychotherapy for young adults and children. In J. Z. Abela, B. L. Hankin, J. Z. Abela, \& B. L. Hankin (Eds.), Handbook of depression in children and adolescents (pp. 250-287). New York, NY: Guilford Press.

Rashid, T., Howes, R. N., \& Louden, R. (2017). Positive psychotherapy: A wellbeing approach to recovery. In M. Slade, L. Oades, A. Jarden, M. Slade, L. Oades, \& A. Jarden (Eds.), Wellbeing, recovery and mental health (pp. 111-132). New York, NY: Cambridge University Press.

Rath, T. (2007). StrengthsFinder 2.0. New York, NY: Gallup Press.

Roberts, L. M., Dutton, J. E., Spreitzer, G. M., Heaphy, E. D., \& Quinn, R. E. (2005a). Composing the reflected best-self portrait: Building pathways for becoming extraordinary in work organizations. Academy of Management Review, 30(4), 712-736.

Roberts, L. M., Spreitzer, G., Dutton, J., Quinn, R., Heaphy, E., \& Barker, B. (2005b). How to play to your strengths. Harvard Business Review, 83(1), 74-80.

Rosa, E. (2013). Social acceleration: A new theory of modernity. New York, NY: Columbia University Press.

Ruch, W., \& Proyer, R. T. (2015). Mapping strengths into virtues: The relation of the 24 VIA-strengths to six ubiquitous virtues. Frontiers in Psychology, 6, 460.

Ruch, W., Proyer, R. T., Harzer, C., Park, N., Peterson, C., \& Seligman, M. E. (2010). Values in action inventory of strengths (VIA-IS). Journal of Individual Differences, 31, 138-149.

Ryan, R. M., \& Deci, E. L. (2000). Self-determination theory and the facilitation of intrinsic motivation, social development, and well-being. American Psychologist, 55(1), 68-78.

Seligman, M. E. (2012). Flourish: A visionary new understanding of happiness and well-being. New York, NY: Simon and Schuster.

Seligman, M. E., Rashid, T., \& Parks, A. C. (2006). Positive psychotherapy. American Psychologist, 61(8), 774.

Seligman, M. E., Steen, T. A., Park, N., \& Peterson, C. (2005). Positive psychology progress: Empirical validation of interventions. American Psychologist, 60(5), 410.

Seligman, M. E. P. (1994). What you can change and what you can't: The guide to successful self-improvement. New York, NY: Knopf.

Sheldon, K. M., \& King, L. (2001). Why positive psychology is necessary. American Psychologist, 56(3), 216-217.

Stander, F. W., Mostert, K., \& de Beer, L. T. (2014). Organisational and individual strengths use as predictors of engagement and productivity. Journal of Psychology in Africa, 24(5), 403-409.

Tims, M., Derks, D., \& Bakker, A. B. (2016). Job crafting and its relationships with person-job fit and meaningfulness: A three-wave study. Journal of Vocational Behavior, 92, 44-53.

Van Wingerden, J., \& Van der Stoep, J. (2018). The motivational potential of meaningful work: Relationships with strengths use, work engagement, and performance. PLOS ONE, 13(6), e0197599. https:// doi.org/10.1371/journal.pone.0197599. 
Van Woerkom, M., Bakker, A. B., \& Nishii, L. H. (2016a). Accumulative job demands and support for strength use: Fine-tuning the JD-R model using COR theory. Journal of Applied Psychology, 101(1), 141-150.

Van Woerkom, M., \& Meyers, M. C. (2015). My strengths count! Human Resource Management, 54(1), 81-103.

Van Woerkom, M., \& Meyers, M. C. (2019). Strengthening personal growth: The effects of a strengths intervention on personal growth initiative. Journal of Occupational and Organizational Psychology, 92(1), 98-121.

Van Woerkom, M., Mostert, K., Els, C., Bakker, A. B., de Beer, L., \& Rothmann, S., Jr. (2016b). Strengths use and deficit correction in organizations: Development and validation of a questionnaire. European Journal of Work and Organizational Psychology, 25(6), 960-975. https://doi.org/10.1080/13594 32X.2016.1193010.

Van Woerkom, M., Oerlemans, W., \& Bakker, A. B. (2015). Strengths use and work engagement: A weekly diary study. European Journal of Work and Organizational Psychology, 25(3), 384-397.

Waters, L. (2011). A review of school-based positive psychology interventions. The Australian Educational and Developmental Psychologist, 28(2), 75-90.

Weber, M., Wagner, L., \& Ruch, W. (2016). Positive feelings at school: On the relationships between students' character strengths, school-related affect, and school functioning. Journal of Happiness Studies, 17(1), 341-355.

Wood, A. M., Linley, P. A., Maltby, J., Kashdan, T. B., \& Hurling, R. (2011). Using personal and psychological strengths leads to increases in well-being over time: A longitudinal study and the development of the strengths use questionnaire. Personality and Individual Differences, 50(1), 15-19.

Publisher's Note Springer Nature remains neutral with regard to jurisdictional claims in published maps and institutional affiliations. 